\title{
Hard tick (Acari: Ixodidae) species of livestock and their seasonal activity in Boyer-Ahmad and Dena cities of Kohgiluyeh and Boyer-Ahmad Province, Southwest of Iran
}

\author{
Zohreh Fatemian ${ }^{1}$, Aref Salehzadeh ${ }^{1}$, Mohammad Mehdi Sedaghat ${ }^{2}$, Zakieh Telmadarraiy², Ahmad Ali Hanafi-Bojd ${ }^{2}$ and \\ Amir Hosein Zahirnia ${ }^{1}$
}

\begin{abstract}
1. Department of Medical Entomology and Vector Control, School of Medicine, Hamadan University of Medical Sciences, Hamadan, Iran; 2. Department of Medical Entomology and Vector Control, School of Public Health, Tehran University of Medical Sciences, Tehran, Iran.

Corresponding author: Aref Salehzadeh, e-mail: a_salehzadeh@yahoo.com

Co-authors: ZF: fatemianzohre@yahoo.com, MMS: sedaghmm@tums.ac.ir,

ZT: telmadarraiy@tums.ac.ir, AAH: aahanafibojd@tums.ac.ir, AHZ: zahirnia@umsha.ac.ir

Received: 05-02-2018, Accepted: 08-08-2018, Published online: 30-09-2018
\end{abstract}

doi: 10.14202/vetworld.2018.1357-1363 How to cite this article: Fatemian Z, Salehzadeh A, Sedaghat MM, Telmadarraiy Z, Hanafi-Bojd AA, Zahirnia AH (2018) Hard tick (Acari: Ixodidae) species of livestock and their seasonal activity in Boyer-Ahmad and Dena cities of Kohgiluyeh and Boyer-Ahmad Province, Southwest of Iran, Veterinary World, 11(9): 1357-1363.

\begin{abstract}
Aim: The present study was carried out to identify the Ixodidae ticks fauna of livestock and their seasonal activity in the cities of Boyer-Ahmad and Dena of Kohgiluyeh Province, south-west of Iran.

Materials and Methods: Hard ticks from sheep, goats, and cattle were collected manually, stored in $70 \%$ ethanol, and identified using morphological characters.

Results: During the study, a total of 1273 hard ticks from four genera, including Rhipicephalus, Hyalomma, Dermacentor, and Haemaphysalis, were collected. Rhipicephalus sanguineus (s.1.) had the highest frequencies in both cities with 62.08 and $62.88 \%$ of collected specimens, followed by Hyalomma scupense with 14.36 and 13.54\% in Boyer-Ahmad and Dena, respectively. Furthermore, Hyalomma marginatum with only one sample or $0.12 \%$ of collected ticks showed the lowest frequencies in the studied areas. Dermacentor marginatus with three samples or $0.37 \%$ was recorded only in Boyer-Ahmad, and Haemaphysalis sulcata with two samples or $0.43 \%$ was recorded only in Dena. In both cities, sheep were the most infested ruminant, and the ears in sheep and goats were the most affected areas. The highest activity was observed in spring, and the lowest activity was observed in winter and autumn.
\end{abstract}

Conclusion: The results of the present study showed that Hyalomma and Rhipicephalus genera were the most widespread genera in the study areas. Regarding the importance of genera, such as Rhipicephalus, Hyalomma, and Haemaphysalis, in transmitting disease agents and the location of Kohgiloyeh and Boyer-Ahmad Province in the routes of migrant birds, further studies are required to elucidate their exact roles in human and livestock health in these areas.

Keywords: domestic ruminants, fauna, Ixodidae ticks, seasonal activity, tick-borne diseases.

\section{Introduction}

Ticks are blood-feeding obligatory ectoparasites, particularly on wild animals [1]. They are important vectors of diseases agent affecting livestock, human, and other vertebrates. About $10 \%$ of the approximately 900 known species of ticks are responsible for the transmission of numerous microorganisms among domestic animals and human [2]. These ectoparasites can transmit a variety of diseases such as CrimeanCongo hemorrhagic fever [3], tularemia, endemic relapsing fever, Lyme disease, anaplasmosis, and rickettsiosis [4]. Some tick-borne pathogens do not only threaten animal lives but also may put human health in

Copyright: Fatemian, et al. Open Access. This article is distributed under the terms of the Creative Commons Attribution 4.0 International License (http://creativecommons.org/licenses/ by/4.0/), which permits unrestricted use, distribution, and reproduction in any medium, provided you give appropriate credit to the original author(s) and the source, provide a link to the Creative Commons license, and indicate if changes were made. The Creative Commons Public Domain Dedication waiver (http:// creativecommons.org/publicdomain/zero/1.0/) applies to the data made available in this article, unless otherwise stated. danger. In addition to transmitting different diseases through biological or mechanical ways, ticks also can have a negative impact on human health through serious annoyance, dermatitis, fatigue, and malnutrition which can be induced by nutrition-based behaviors [5-7]. Tick paralysis in human and animals [8], as a result of the secretion of toxic substances in their saliva, is another tick-borne problem. In comparison with other blood-feeding arthropods, usually hard ticks feed for extended periods of time [4,9], which, in turn, increases the chances of transmission of diseases [10]. It is believed that pathogens transmitted by ticks are responsible for more than 100,000 cases of human disease conditions throughout the world [11] and despite the use of antiparasitic chemicals to combat the parasite, due to resistance, the control of ticks has raised concern in public and health authorities [12].

Studies on ticks in Iran were first conducted by Delpy, thereafter, Abbasian-Lintzen between 1960 and 1961 and Mazloum during 1968 and 1971 collected a list of maturated ticks from livestock [13-15]. One 
of the most comprehensive studies on tick's species was conducted by Mazloum [14], who showed the geographical distribution, the hosts, active seasons, and their dispersion in different regions of the country. Hoogstraal and Valdes [16] studied the hard ticks feeding on sheep and wild goat. Nabian et al. [17], in their study, reported a list of tick's species on domestic animals in Azerbaijan Saharqi. Salari-Lak et al. [18] also reported a list of hard ticks and soft tick's species in Azerbaijan Qarbi. Further, Rahbari et al. [19] published primary reports on the distribution of various species of ticks in livestock of four geographical areas of Iran. An investigation of fauna, geographic distribution, and seasonal activity of hard ticks in Sari city resulted in collection of six species belonging to six genera of hard ticks including Rhipicephalus bursa, Hyalomma detritum, Boophilus annulatus, Haemaphysalis punctata, Ixodes ricinus, and Dermacentor marginatus [20]. Riabi and Atarodi [21] identified the fauna of hard ticks in domestic animals in the southern part of Khorasan Razavi Province and then compared them with other areas of this Province.

The majority of the domestic ruminants of Iran exist in Kohgiluyeh and Boyer-Ahmad Province. Therefore, this Province is the most important animal husbandry center in the country and that relocating them between the tropical and the cold regions (due to the seasonal changes of ambient temperature) may cause the distribution of diseases by tick infestation. Hence, this study was designed to determine the status of the diversity of ixodid ticks, seasonal distribution, topology, and their hosts which are very important in monitoring any programs to combat ectoparasites of ruminants and related diseases.

\section{Materials and Methods}

\section{Ethical approval}

This study obtained ethical clearance from the Ethics Committee of Hamadan University of Medical Sciences.

\section{Study areas}

Kohgiluyeh and Boyer-Ahmad is located in the western part of Iran between latitude $30^{\circ} 9^{\prime}$ and $31^{\circ} 32^{\prime}$ $\mathrm{N}$ and longitude $49^{\circ} 57^{\prime}$ and $50^{\circ} 42^{\prime} \mathrm{E}$. This Province with an area of about $16,249 \mathrm{~km}^{2}$ is a mountainous land and divided geographically into two large areas of the cold and tropical regions with average rainfall of $600-800 \mathrm{~mm}$ and $300-500 \mathrm{~mm}$, respectively. The warmest months are July and August and the coldest months are January and December with average temperatures of $25-27^{\circ} \mathrm{C}$ and $4-5^{\circ} \mathrm{C}$, respectively. The maximum and minimum registered temperature is 40 and $-25^{\circ} \mathrm{C}$ in July and February, respectively. Dena is the tallest mountain in the Zagros Range, with more than 40 peaks higher than $4000 \mathrm{~m}$ and the highest peak with an elevation of $4409 \mathrm{~m}$ above sea level. Kohgiluyeh and Boyer-Ahmad is one of the southern Provinces of Iran. It is in the neighborhood with five Provinces of the country, from the east with Isfahan and
Fars Provinces, from the south with Bushehr Province, from the west with the Khuzestan, and finally from the north with Chaharmahal and Bakhtiari Province. Agriculture and animal husbandry are the major occupations of the villagers of Boyer-Ahmad and Dena cities. Cattle are mainly kept and raised in both traditional and semi-industrial forms in animal husbandries and villages. Kohgiluyeh and Boyer-Ahmad can be divided into two: tropical and the cold regions.

\section{Ticks collection and identification}

Ticks were collected manually from all different climate zones including plains and mountains once a month and continued for 12 months from winter of 2015 until the fall of 2016. The number of sampling was commensurate with the extent and situation of the study areas. Thus, 19 sampling sites (12 sites in Boyer-Ahmad and 7 sites in Dena city) were selected, and 600 ruminants were checked for tick infestation. Due to the dominance of mountainous area in Dena ( $80 \%$ mountainous and $20 \%$ plains), most sites were selected in these areas (4 spots on the mountain and 2 spots on the plains). Furthermore, Boyer-Ahmad is dominated by plain areas, and only $40 \%$ of this region is situated in mountainous areas, so the selected numbers of places in the plains were more than places in the mountains ( 3 spots in the plains and 2 spots in the mountains). Sampling was done on all parts of the body of livestock (cattle, sheep, and goats) and the sample size was determined based on a previous study [22]. Two important criteria in the determination of sampling sites were the geographical direction and topographical status. After restraining animals, the different areas of their bodies (head and neck, under the tail, around the anus and perineum, groin, ears, and breast) were systematically checked for the presence of ticks. To remove the ticks, cotton soaked in alcohol or chloroform was put on each tick and, thereafter, the ticks were removed using forceps. All samplings were done with care not to harm the ticks. Subsequently, the ticks were placed into tubes or cans containing $70 \%$ ethyl alcohol and $5 \%$ glycerin. The necessary information were written on all the tubes or cans including date of catching, name of the village, name of the owner of the animal, type of the animal, age, gender, and code of the livestock. After the samples were transferred to the laboratory, genus and species were diagnosed under stereomicroscope on the basis of morphological character and were compared with the characteristics presented in valid taxonomic keys [23-26] and species of the standard collection.

\section{Statistical analysis}

Data were analyzed using Statistical Package for the Social Sciences, (SPSS 20 [IBM, USA]).

\section{Results}

During the period of the study, a total of 1273 ticks (458 ticks in Dena and 815 ticks in BoyerAhmad) were collected. About 68.1\% (555) of the 
specimens were from sheep, $22.33 \%$ (182) from goat, and 9.57\% (78) from cattle in Boyer-Ahmad. Furthermore, in Dena, 52.18\% (239) of specimens were collected from sheep, $37.77 \%$ (173) from goat, and $10.05 \%$ (46) from cattle. The rate of infested ruminants in the spring was more than the other seasons, and the least value was observed in winter. Tables- 1 and 2 show the seasonal abundance of the hard ticks in Dena and Boyer-Ahmad cities, respectively. In Boyer-Ahmad, spring was the most active season, and $67.73 \%$ of ticks were collected during this season, but only $1.1 \%$ of ticks were collected during winter. Furthermore, in Dena, 55.24\% of ticks were collected in the spring, and only $6.11 \%$ of them were collected in the autumn. Rhipicephalus, Hylomma, and Dermacentor were the three genera of ixodid ticks, which were identified in Boyer-Ahmad including Rhipicephalus sanguineus (s.1.) (62.08\%), $R$. bursa (12.52\%), Rhipicephalus turanicus (1.72\%), Rhipicephalus nymph (0.12\%), Hyalomma asiaticum $(0.37 \%), H$. detritum $(0.12 \%)$, Hylomma excavatum (1.1\%), Hyalomma marginatum (0.12\%), Hyalomma scupense (14.36\%), Hylomma sp. (1.35\%), Hylomma nymph (5.77\%), and D. marginatus $(0.37 \%)$. Furthermore, three genera of ixodid ticks (Rhipicephalus, Hylomma, and Haemaphysalis) were identified in Dena, which includes $R$. sanguineus (s.1.) (62.88\%), R. bursa $(12.45 \%), R$. turanicus $(1.32 \%), R$. nymph $(0 / 43 \%)$, H. scupense $(13.54 \%)$, H. marginatum $(0.22 \%)$, H. asiaticum $(0.43 \%)$, H. nymph $(6.77 \%)$, Hylomma sp. $(1.53 \%)$, and Haemaphysalis sulcata $(0.43 \%)$. $R$. sanguineus (s.1.) was the most abundant hard tick in the studied cities.

Figures- 1 and 2 show the topological preference of hard ticks in both cities. In Boyer-Ahmad, 85.28\% of ticks were collected from the plains and $14.72 \%$ from the mountainous areas, whereas in Dena city, only $29.33 \%$ of ticks were collected from the plains and $70.67 \%$ of samples were obtained from the mountainous area. The genus Rhipicephalus was the most abundant collected from sheep, whereas Hyalomma was the most abundant genus collected from cattle (Tables-3 and 4). H. asiaticum, H. excavatum, $H$. marginatum, and $R$. turanicus only were found on sheep.

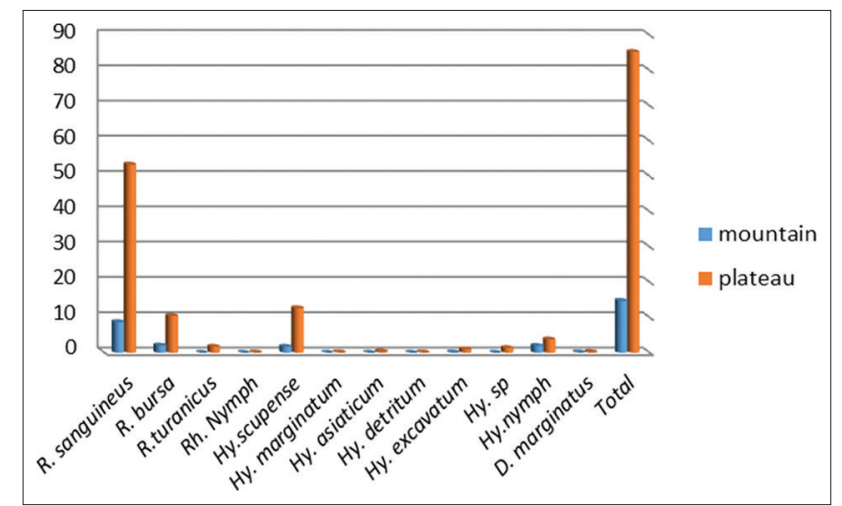

Figure-1: Topological preference of hard ticks collected in the Boyer-Ahmad city.

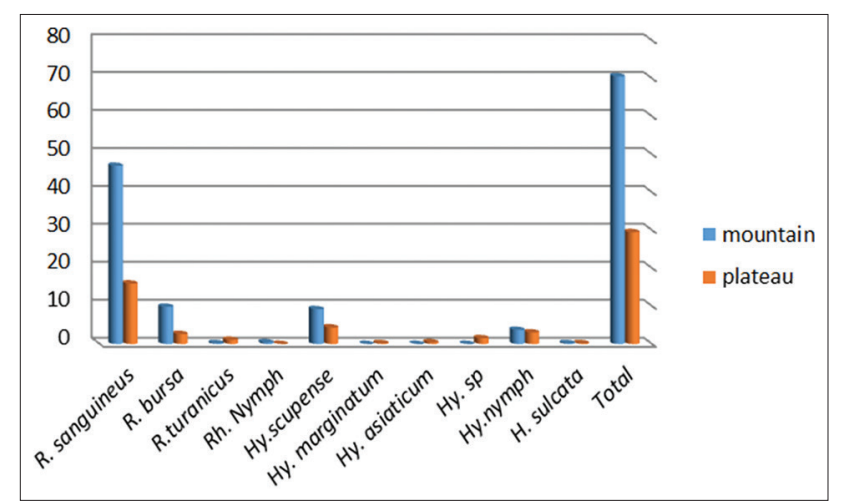

Figure-2: Topological preference of hard ticks collected in the Dena city.

Table-1: Seasonal abundance of hard ticks in the Boyer-Ahmad city.

\begin{tabular}{|c|c|c|c|c|c|c|c|c|c|c|c|}
\hline \multirow[t]{3}{*}{ Species } & \multirow[t]{3}{*}{ n (\%) } & \multicolumn{10}{|c|}{ Season } \\
\hline & & \multicolumn{2}{|c|}{ Spring } & \multicolumn{2}{|c|}{ Summer } & \multicolumn{2}{|c|}{ Autumn } & \multicolumn{2}{|c|}{ Winter } & \multicolumn{2}{|c|}{ Total } \\
\hline & & Female & Male & Female & Male & Female & Male & Female & Male & Female & Male \\
\hline$R$. sanguineus & $506(62.08)$ & 173 & 244 & 17 & 37 & 9 & 17 & 5 & 4 & 204 & 302 \\
\hline R. bursa & $102(12.52)$ & 62 & 37 & 1 & 2 & 0 & 0 & 0 & 0 & 63 & 39 \\
\hline R. turanicus & $14(1.72)$ & 0 & 14 & 0 & 0 & 0 & 0 & 0 & 0 & 0 & 14 \\
\hline R. nymph* & $1(0.12)$ & - & - & - & - & - & - & - & - & & - \\
\hline H. asiaticum & $3(0.37)$ & 0 & 2 & 0 & 0 & 0 & 1 & 0 & 0 & 0 & 3 \\
\hline H. detritum & $1(0.12)$ & 1 & 0 & 0 & 0 & 0 & 0 & 0 & 0 & 1 & 0 \\
\hline H. excavatum & $9(1.1)$ & 0 & 1 & 0 & 2 & 3 & 3 & 0 & 0 & 3 & 6 \\
\hline H. marginatum & $1(0.12)$ & 0 & 0 & 0 & 0 & 0 & 1 & 0 & 0 & 0 & 1 \\
\hline H. scupense & $117(14.36)$ & 0 & 12 & 37 & 58 & 5 & 5 & 0 & 0 & 42 & 75 \\
\hline Hyalomma spp. & $11(1.35)$ & 3 & 0 & 1 & 0 & 7 & 0 & 0 & 0 & 11 & 0 \\
\hline H. nymph* & $47(5.77)$ & - & - & - & - & - & - & - & - & - & - \\
\hline D. marginatus & $3(0.37)$ & 2 & 1 & 0 & 0 & 0 & 0 & 0 & 0 & 2 & 1 \\
\hline Total & $815(100)$ & 241 & 311 & 54 & 99 & 24 & 27 & 5 & 4 & 326 & 441 \\
\hline
\end{tabular}

*Sex in the nymphs is unknown. $R$. sanguineus=Rhipicephalus sanguineus, $R$. bursa=Rhipicephalus bursa,

$R$. turanicus=Rhipicephalus turanicus, $R$. Nymph=Rhipicephalus nymph, $H$. asiaticum=Hyalomma asiaticum,

$H$. detritum =Hyalomma detritum, $H$. excavatum=Hylomma excavatum, $H$. marginatum=Hyalomma marginatum, $H$. scupense=Hyalomma scupense, $H$. nymph=Hylomma nymph, D. marginatus=Dermacentor marginatus 
Table-2: Seasonal abundance of hard ticks in the Dena city.

\begin{tabular}{|c|c|c|c|c|c|c|c|c|c|c|c|}
\hline \multirow[t]{3}{*}{ Species } & \multirow[t]{3}{*}{ n (\%) } & \multicolumn{10}{|c|}{ Season } \\
\hline & & \multicolumn{2}{|c|}{ Spring } & \multicolumn{2}{|c|}{ Summer } & \multicolumn{2}{|c|}{ Autumn } & \multicolumn{2}{|c|}{ Winter } & \multicolumn{2}{|c|}{ Total } \\
\hline & & Female & Male & Female & Male & Female & Male & Female & Male & Female & Male \\
\hline R. sanguineus & $288(62.88)$ & 93 & 106 & 12 & 30 & 8 & 10 & 21 & 8 & 134 & 154 \\
\hline R. bursa & $57(12.45)$ & 40 & 11 & 2 & 1 & 0 & 0 & 0 & 3 & 42 & 15 \\
\hline R. turanicus & $6(1.32)$ & 0 & 1 & 0 & 0 & 0 & 0 & 0 & 5 & 0 & 6 \\
\hline R. nymph* & $2(0.43)$ & - & - & - & - & - & - & - & - & & - \\
\hline H. scupense & $62(13 / 54)$ & 0 & 1 & 12 & 47 & 1 & 1 & 0 & 0 & 13 & 49 \\
\hline H. marginatum & $1(0.22)$ & 0 & 0 & 0 & 0 & 0 & 1 & 0 & 0 & 0 & 1 \\
\hline H. asiaticum & $2(0.43)$ & 0 & 0 & 0 & 0 & 0 & 2 & 0 & 0 & 0 & 2 \\
\hline Hyalomma spp. & $7(1.53)$ & 0 & 0 & 1 & 2 & 4 & 0 & 0 & 0 & 5 & 2 \\
\hline H. nymph* & $31(6.77)$ & 0 & 0 & 0 & 0 & 0 & 0 & 0 & 0 & 0 & 0 \\
\hline H. sulcata & $2(0.43)$ & 1 & 0 & 0 & 0 & 0 & 0 & 0 & 1 & 1 & 1 \\
\hline Total & $458(100)$ & 134 & 119 & 27 & 80 & 13 & 14 & 21 & 17 & 195 & 230 \\
\hline
\end{tabular}

*Sex of nymphs is unknown. $R$. sanguineus=Rhipicephalus sanguineus, $R$. bursa=Rhipicephalus bursa,

R. turanicus=Rhipicephalus turanicus, $R$. nymph=Rhipicephalus nymph, H. scupense=Hyalomma scupense, $H$. marginatum=Hyalomma marginatum, $H$. asiaticum=Hyalomma asiaticum, $H$. nymph=Hylomma nymph, H. sulcate=Haemaphysalis sulcata

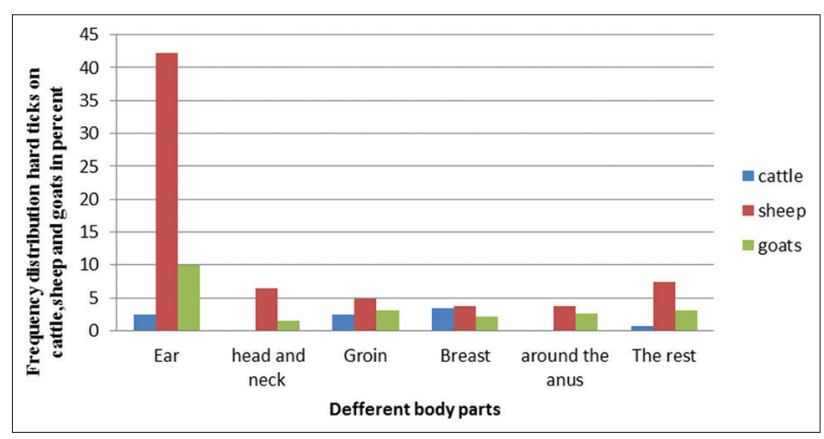

Figure-3: Body-site distribution of hard ticks collected from cattle, sheep, and goats in the city of Boyer-Ahmad.

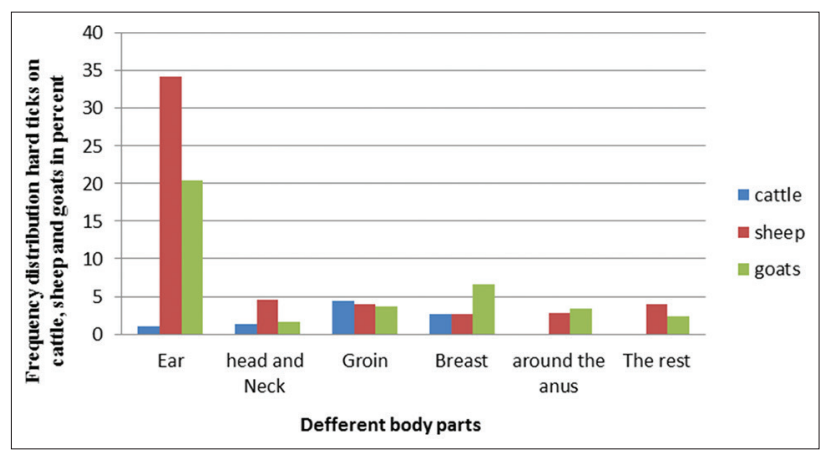

Figure-4: Body-site distribution of hard ticks collected from cattle, sheep, and goats in the city of Dena.

Figures-3 and 4 show the body-site distribution of ticks collected from the ruminants. As shown in the figures, the greatest number of ticks collected from sheep and goats was from the regions of their ears, whereas most of the ticks collected from cattle were from their groin and breast regions.

\section{Discussion}

The present study was conducted throughout a whole year, with an attempt to determine comprehensive information about fauna and geographical distribution of various species of ticks in different seasons, as well as host preference and body-site distribution in Boyer-Ahmad and Dena cities.
A total of 1273 hard ticks from cattle, sheep, and goats, belonging to four genera (Rhipicephalus, Hylomma, Haemaphysalis, and Dermacentor), were collected. The reported genera in this research have been considered as very important hard ticks from the medical and veterinary perspective in Iran $[4,11,19]$.

$R$. sanguineus (s.1.), which is also known as the brown dog tick, was most abundant and widespread tick species throughout the studied areas. The similar result had also been reported in other studies in Iran $[6,16,25,26]$ and throughout the world [27]. Due to its endophilous nature, this species is adapted to live within human dwellings and is active throughout the year. Some reports suggested that in warm climate or regions with longer summer, $R$. sanguineus (s.l.) readily attach to man [28]. This, in turn, increases the risk of transmission of pathogens such as Rickettsia conorii to human and Ehrlichia canis or Babesia canis vogeli to dogs [29]. $R$. sanguineus (s.1.), which has been considered as a species complex and parasitizes a wide range of vertebrates [30], has also been suggested as suspected vectors of sheep anaplasmosis in the central part of Iran [31].

The results of the present study showed that sheep and goats were infested to a greater extent than cattle $(36.76,22.15$, and $3.53 \%$ infestation, respectively). These results are in line with those reported in studies by Abbasian-Lintzen [13] and Mazlum [14] and a similar study in Golestan Province, north of Iran [16]. Adult $R$. bursa has been reported as a vector of Babesia ovis [32]. This species had a similar frequency in both cities, confirming the adaptability of this parasite to different geographical conditions and hosts [33]. The distribution of $R$. bursa by livestock and other hosts can increase the chances of disease transmission. $R$. turanicus is distributed mainly in Africa and Asia and a large part of the Mediterranean to India and China [34]. Although in a study conducted by Razmi et al. [35] in the North and South of Khorasan Razavi, R. turanicus was reported as 
Table-3: The host diversity of hard tick species in the Dena city.

\begin{tabular}{lccc}
\hline Species & \multicolumn{3}{c}{ Host } \\
\cline { 2 - 4 } & Cattle & Sheep & Goat \\
\hline R. sanguineus & 7 & 154 & 127 \\
R. bursa & 3 & 26 & 28 \\
R. turanicus & 0 & 0 & 6 \\
R. nymph & 2 & 0 & 0 \\
H. scupense & 27 & 28 & 7 \\
H. marginatum & 0 & 1 & 0 \\
H. asiaticum & 0 & 2 & 0 \\
Hyalomma spp. & 2 & 5 & 0 \\
H. nymph* & 5 & 22 & 4 \\
H. sulcata & 0 & 1 & 1 \\
Total & 46 & 239 & 173 \\
\hline
\end{tabular}

*Sex of Nymphs is unknown. $R$. sanguineus=Rhipicephalus sanguineus, $R$. bursa=Rhipicephalus bursa,

$R$. turanicus=Rhipicephalus turanicus,

$R$. nymph=Rhipicephalus nymph, H. scupense=Hyalomma scupense, $H$. marginatum =Hyalomma marginatum, $H$. asiaticum $=$ Hyalomma asiaticum, $H$. nymph $=$ Hylomma nymph, $H$. sulcate $=$ Haemaphysalis sulcata

Table-4: The host diversity of hard tick species in Boyer-Ahmad city.

\begin{tabular}{lccc}
\hline Species & \multicolumn{3}{c}{ Host } \\
\cline { 2 - 4 } & Cattle & Sheep & Goat \\
\hline R. sanguineus & 38 & 314 & 154 \\
R. bursa & 0 & 89 & 13 \\
R. turanicus & 0 & 14 & 0 \\
R. nymph & 0 & 1 & 0 \\
H. asiaticum & 0 & 3 & 0 \\
H. detritum & 0 & & 1 \\
H. excavatum & 0 & 9 & 0 \\
H. marginatum & 0 & 1 & 0 \\
H. scupense & 40 & 70 & 7 \\
Hyalomma spp. & 0 & 11 & 0 \\
H. nymph* & 0 & 41 & 6 \\
D. marginatus & 0 & 2 & 1 \\
Total & 78 & 555 & 182 \\
\hline
\end{tabular}

*Sex of nymphs is unknown. $R$. sanguineus=Rhipicephalus sanguineus, $R$. bursa=Rhipicephalus bursa,

$R$. turanicus $=$ Rhipicephalus turanicus, $R$. nymph $=$ Rhipicephalus nymph, $H$. asiaticum =Hyalomma asiaticum,

$H$. detritum $=$ Hyalomma detritum, $H$. excavatum $=$ Hylomma excavatum, $H$. marginatum =Hyalomma marginatum, $H$. scupense $=$ Hyalomma scupense, $H$. nymph=Hylomma nymph, D. marginatus $=$ Dermacentor marginatus

dominant species, and the frequencies of this species in Boyer-Ahmad and Dena were found to be only $1.72 \%$ and $1.32 \%$ of the collected ixodid ticks, respectively.

In addition to mammals, birds are potential hosts of ixodid ticks [36]. As a result of the to and fro movement of wild bird from Iran, it is probable that some species of Hyalomma or Haemaphysalis, which are carried by migratory bird [37,38], can transmit some disease agents between Iran and other countries. Ticks of genus Haemaphysalis are found in all weather conditions and geographical areas but are more prevalent in wet weather [18]. In the present study, $H$. sulcata was collected only from Dena city. Since Dena is situated in higher altitude, the difference in weather and other environmental factors may justify the absence of this species from BoyerAhmad. D. marginatus the only known species of the genus Dermacentor was collected from sheep and goat of Boyer-Ahmad. These species are distributed in many parts of Western Europe to Western Kazakhstan, especially in the lowlands and deciduous forested areas [27]. It has also been reported in different parts of Iran by some researchers [26,39]. D. marginatus and some other species of Dermacentor are known vectors of Rickettsia slovaca and Rickettsia raoultii [40].

In the present study, the number of collected ticks was higher in spring and summer which indicate the dependence of ticks to ambient temperature. The importance of environmental conditions such as enough rainfall and heat on the activity of ticks have also been mentioned by other researchers [27]. The region has an appropriate climate, vegetation cover, and sufficient heat suitable for completing the life cycle of ticks in warmer seasons. The study was conducted in plain and mountainous areas of BoyerAhmad and Dena. In Boyer-Ahmad, 85.28\% of ticks were collected from the plain areas, whereas only $29.33 \%$ of the ticks were obtained from the plain areas of Dena. On the contrary, $70.67 \%$ of ticks were collected from the mountainous regions Dena.

The results of the present study showed that Hylomma and Rhipicephalus genera were the most widespread genera distributed in the study areas. Regarding the role of $R$. bursa in transmitting Babesia spp. in cattle, sheep, goat, horse and dog [41], and Hylomma spp. in transmitting Theileria [42] and Crimean-Congo haemorrhagic fever [43], as well as the role of Haemaphysalis spp. in circulation of some rickettsial diseases [44], further studies are required to elucidate their exact roles in the epidemiology of human and animal diseases. Furthermore, some Iranian Provinces including Kohgiluyeh and BoyerAhmad are in the migration routes of birds [45], and as such, the likelihood of spreading tick-borne diseases by migratory bird to and fro Iran should be considered.

\section{Conclusion}

The results of the present study can provide a basis for the adoption of an effective strategy for the management of hard ticks in livestock of Kohgiluyeh and Boyer-Ahmad. Due to the expanded livestock industry, appropriate situation for the development and dispersion of hard ticks, the status of tick-borne diseases and the rate of infestation of animals should be monitored routinely. Moreover, the regular and accurate dipping of livestock can be one of the most important methods to combat the mentioned ectoparasites and related diseases, especially in sheep and goats. 


\section{Authors' Contributions}

AS, ZT and AHZ conceptualized and designed the study. ZF collected the samples. ZF, AS and ZT identified the samples. AS and ZF analyzed data and drafted the manuscript. MMS, AS, AHZ, AAH and ZT supervised the project. All authors discussed the results and implications and commented on the manuscript at all stages. All authors read and approved the final manuscript.

\section{Acknowledgments}

The authors would like to thank the Deputy of Research and Technology of Hamadan University of Medical Sciences, Hamadan, Iran (Project no. 9505052510), for financial support.

\section{Competing Interests}

The authors declare that they have no competing interests.

\section{References}

1. Wall, R. and Shearer, D. (1997) Veterinary Entomology. In: Ticks (Acari). $1^{\text {st }}$ ed. Chapman and Hall, UK. p96-139.

2. Jongejan, F. and Uilenberg, G. (2004) The global importance of ticks. Parasitology, 129 Suppl: S3-S14.

3. Papa, A., Tsergouli, K., Tsioka, K. and Mirazimi, A. (2017) Crimean-congo hemorrhagic fever: Tick-host-virus interactions. Front. Cell. Infect. Microbiol., 7: 213.

4. de la Fuente, J., Contreras, M., Estrada-Peña, A. and Cabezas-Cruz, A. (2017) Targeting a global health problem: Vaccine design and challenges for the control of tick-borne diseases. Vaccine, 35(38): 5089-5094.

5. Mansfield, K.L., Jizhou, L., Phipps, L.P. and Johnson, N. (2017) Emerging tick-borne viruses in the twenty-first century. Front. Cell. Infect. Microbiol., 7: 298.

6. Jafarbekloo, A., Vatandoost, H., Davari, A., Faghihi, F., Bakhshi, H., Ramzgouyan, M., Nasrabadi, M. and Telmadarraiy, Z. (2014) Distribution of tick species infesting domestic ruminants in borderline of Iran-Afghanistan. J. Biomed. Sci. Eng., 7: 982-987.

7. Sofizadeh, A., Telmadarraiy, Z., Rahnama, A., GorganliDavaji, A. and Hosseini-Chegeni, A. (2014) Hard tick species of livestock and their bioecology in Golestan province, North of Iran. J. Arthropod Borne Dis., 8(1): 108-116.

8. Whitfield, Z., Kelman, M. and Ward, M.P. (2017) Delineation of an endemic tick paralysis zone in southeastern Australia. Vet. Parasitol., 247: 42-48.

9. Sonenshine, D.E. (1991) Biology of Ticks. Oxford University Press, New York. p1-449.

10. Richards, S., Langley, R., Apperson, C. and Watson, E. (2017) Do tick attachment times vary between different tick-pathogen systems? Environments, 4(2): 37.

11. Jalil, W.I. and Zenad, M.M. (2016) Isolation of aerobic bacteria from ticks infested sheep in Iraq. Asian Pac. J. Trop. Biomed, 6(1): 67-70.

12. Rodriguez-Vivas RI, Jonsson NN, Bhushan C. (2017) Strategies for the control of Rhipicephalus microplus ticks in a world of conventional acaricide and macrocyclic lactone resistance. Parasitol. Res., 117(1): 3-29.

13. Abbasian-Lintzen, R. (1960) A preliminary list of ticks from southeastern of Iran and their distributional data. Acarologia. 2(1): 43-61.

14. Mazloum, Z. (1971) Ticks of domestic animals in Iran: Geographical distribution, host relation and seasonal activity. J. Vet. Res., 27: 1-32.

15. Nasiri, A., Telmadarraiy, Z., Vatandoost, H., Chinika, R.S., Moradi, M., Oshaghi, M., Salim-Abadi, Y. and Sheikh, Z.
(2010) Tick infestation rate of sheep and their distribution in Abdanan County, Ilam Province, Iran, 2007-2008. Iran. J. Arthropod Borne Dis., 4(2): 56-60.

16. Hoogstraal, H. and Valdez, R. (1980) Ticks (Ixodoidea) from wild sheep and goats in Iran and medical and veterinary implications. Fieldiana Zool., 6: 1-16.

17. Nabian, S., Rahbari, S., Shayan, P. and Haddadzadeh, H.R. (2007) Current status of tick fauna in north of Iran. Iran. J. Parasitol., 2(1): 12-17.

18. Salari-Lak, S., Telmadarraiy, Z., Entezar-Mahdi, R. and Kia, E.B. (2008) Seasonal activity of ticks and their importance in tick-borne infectious diseases in West Azerbaijan, Iran. J. Arthropod Borne Dis., 2(2): 28-34.

19. Rahbari, S., Nabian, S. and Shayan, P. (2007) Primary report on distribution of tick fauna in Iran. Parasitol. Res., 101(2): 175-177.

20. Asgarian, F., Enayati, A.A., Amouei, A. and YazdaniCharati, J. (2011) Fauna, geographical distribution and seasonal activity of hard ticks from Sari township in 20072008. J. Mazandaran Univ. Med. Sci., 21(83): 25-33.

21. Riabi, H. and Atarodi, A. (2014) Faunistic study of hard ticks (Ixodidae) of domestic ruminants in the Southern Khorasan-e-Razavi in comparing with other regions of the province in 2012 Iran. J. Vet. Adv., 4(5): 508-515.

22. Davari, B., Alam, F.N., Nasirian, H., Nazari, M., Abdigoudarzi, M. and Salehzadeh, A. (2017) Seasonal distribution and faunistic of ticks in the Alashtar county (Lorestan Province), Iran. Pan Afr. Med. J., 27: 284.

23. Hosseini-Chegeni, A., Hosseini, R., Tavakoli, M., Telmadarraiy, Z. and Abdigoudarzi, M. (2013) The Iranian hyalomma (Acari: Ixodidae) with a key to the identification of male species. Persian J. Acarol., 2(3): 503-529.

24. Walker, A.R., Bouattour, A., Camicas, J.L., Estrada-Peña, A., Horak, I.G., Latif, A.A., Pegram, R.G and Preston, P.M. (2003) Ticks of Domestic Animals in Africa: A Guide to Identification of Species. Bioscience Reports. Edinburgh, United Kingdom. p1-221.

25. Estrada-Peña, A., Bouattour, A., Camicas, J.L. and Walker, A.R. (2004) Ticks of Domestic Animals in the Mediterranean Region: A Guide to Identification of Species. University of Zaragoza, Zaragoza. p131.

26. Telmadarraiy, Z. and Hosseini-Chegini, A. (2010) Glossary of Diagnostic Terms of Ticks. Ghashye 978-600-5708-10-3, Tehran.

27. Gray, J., Dautel, H., Estrada-Peña, A., Kahl, O. and Lindgren, E. (2009) Effects of climate change on ticks and tick-borne diseases in Europe. Interdiscip. Perspect. Infect. Dis.,Article ID 593232.

28. Dantas-Torres, F. (2010) Biology and ecology of the brown dog tick, Rhipicephalus sanguineus. Parasit. Vectors, 3(1): 26.

29. Parola, P. and Raoult, D. (2001) Ticks and tickborne bacterial diseases in humans: An emerging infectious threat. Clin. Infect. Dis., 32(6): 897-928.

30. Coimbra-Dores, M.J., Nunes, T., Dias, D. and Rosa, F. (2016) Rhipicephalus sanguineus (Acari ixodidae) species complex: Morphometric and ultrastructural analyses. Exp. Appl. Acarol., 70: 455-468.

31. Noaman, V., Abdi-goudarzi, M., Nabinejad, A.R., Heidari, M.R. and Khalilifard, M. (2009) Identification of hard ticks of domestic ruminants in two ecological zones of Isfahan province, Iran. J. Pajouhesh Sazandegi, 77: 88-95.

32. Erster, R.A., Wolkomirsky, R., Leibovich, B., Savitzky, I. and Shkap, V. (2016) Transmission of Babesia ovis by different Rhipicephalus bursa developmental stages and infected blood injection. Ticks Tick Borne Dis., 7(1): 13-19.

33. Ferrolho, J., Antunes, S., Santos, A.S., Velez, R., Padre, L., Cabezas-Cruz, A., Santos-Silva, M.M. and Domingos, A. (2016) Detection and phylogenetic characterization of Theileria spp. and Anaplasma marginale in Rhipicephalus bursa in Portugal. Ticks Tick Borne Dis., 7(3): 443-448.

34. Dantas-Torres F, Latrofa MS, Annoscia G, Giannelli A, Parisi A, Otranto D. (2013) Morphological and genetic 
diversity of Rhipicephalus sanguineus sensu lato from the New and Old Worlds. Parasit Vectors. 6:213.

35. Razmi, G., Najarnejad, V. and Rashtibaf, M. (2011) Determination the frequency of Ixodid ticks on the sheep in Khorasan Razavi province, Iran. Arch. Razi Inst., 66(2): 129-132.

36. Hasle, G. (2013) Transport of ixodid ticks and tick-borne pathogens by migratory birds. Front. Cell. Infect. Microbiol., 3: 48 .

37. Palomar, A., Portillo, A., Mazuelas, D., Roncero, L., Arizaga, J., Crespo, A., Gutiérrez, Ó., Márquez, F.J., Cuadrado, J.F., Eiros, J.M. and Oteo, J.A. (2016) Molecular analysis of crimean-congo hemorrhagic fever virus and rickettsia in Hyalomma marginatum ticks removed from patients (Spain) and birds (Spain and Morocco), 20092015. Ticks Tick Borne Dis., 7(5): 983-987.

38. Hornok, S., Flaisz, B., Takács, N., Kontschán, J., Csörgö, T., Csipak, Á., Jaksa, B.R. and Kováts, D. (2016) Bird ticks in Hungary reflect Western, Southern, Eastern flyway connections and two genetic lineages of Ixodes frontalis and Haemaphysalis concinna. Parasit. Vectors, 9: 101.

39. Taheriyan, S.M.R., Kayedi, M.H., Hosseini-Chegeni, A. and Behrahi, A. (2014) Identification of Genus and species of hard and soft ticks collected from livestock in Khorramabad districts, Lorestan Province, Iran. Yafte J. Med. Sci., 16(2): 5-16.

40. Špitalská, E., Stefanidesová, K., Kocianová, E. and Boldiš, V. (2012) Rickettsia slovaca and Rickettsia raoultii in Dermacentor marginatus and Dermacentor reticulatus ticks from Slovak Republic. Exp. Appl. Acarol., 57(2): 189-197.

41. Chao, L., Yeh, S.T., Hsieh, C.K. and Shih, C.M. (2016) First detection and molecular identification of Babesia vogeli from Rhipicephalus sanguineus (Acari: Ixodidae) in Taiwan. Exp. Appl. Acarol., 68(4): 539-551.

42. Meng, K., L.I. Z., Wang, Y., Jing, Z., Zhao, X., Liu, J., Cai, D., Zhang, L., Yang, D., Wang, S. (2014) PCR-based detection of Theileria annulata in Hyalomma asiaticum ticks in Northwestern China. Ticks Tick Borne Dis., 5(2): 105-106.

43. Cajimat, M., Rodriguez, S.E., Schuster, I.U.E., Swetnam, D.M., Ksiazek, T.G., Habela, MA., Negredo, A.I., Estrada-Peña, A., Barrett, A.D.T. and Bente, D.A. (2017) Genomic characterization of crimean-congo hemorrhagic fever virus in hyalomma tick from Spain, 2014. Vector Borne Zoonotic Dis., 17(10): 714-719.

44. Chisu, V., Leulmi, H., Masala, G., Piredda, M., Foxi, C. and Parola, P. (2017) Detection of Rickettsia hoogstraalii, Rickettsia helvetica, Rickettsia massiliae, Rickettsia slovaca and Rickettsia aeschlimannii in ticks from Sardinia, Italy. Ticks Tick Borne Dis., 8(3): 347-352.

45. Combreau, O., Riou, S, Judas, J., Lawrence, M. and Launay, F. (2011) Migratory pathways and connectivity in Asian houbara bustards: Evidence from 15 years of satellite tracking. PLoS One, 6(6): e20570. 